\title{
THE
}

\section{Efficient Detection of Phthalate Esters in Human Saliva via Fluorescence Spectroscopy}

\author{
Dana J. DiScenza \\ University of Rhode Island \\ Melissa A. Smith \\ University of Rhode Island \\ Lauren E. Intravaia \\ University of Rhode Island \\ Mindy Levine \\ University of Rhode Island, m_levine@uri.edu \\ Follow this and additional works at: https://digitalcommons.uri.edu/chm_facpubs
}

The University of Rhode Island Faculty have made this article openly available.

Please let us know how Open Access to this research benefits you.

This is a pre-publication author manuscript of the final, published article.

Terms of Use

This article is made available under the terms and conditions applicable towards Open Access

Policy Articles, as set forth in our Terms of Use.

\section{Citation/Publisher Attribution}

Dana J. DiScenza, Melissa A. Smith, Lauren E. Intravaia \& Mindy Levine (2018) Efficient Detection of Phthalate Esters in Human Saliva via Fluorescence Spectroscopy, Analytical Letters, DOI: 10.1080/ 00032719.2018 .1471086

Available at: http://dx.doi.org/10.1080/00032719.2018.1471086 
TITLE: Efficient Detection of Phthalate Esters in Human Saliva via Fluorescence Spectroscopy

SHORT TITLE: Fluorimetric Detection of Phthalates in Saliva

Dana J. DiScenza, Melissa A. Smith, Lauren E. Intravaia, and Mindy Levine*

\section{AUTHOR DETAILS}

\section{Corresponding Author}

*Dr. Mindy Levine, Department of Chemistry, University of Rhode Island, 140 Flagg Road, Kingston, RI 02881; mindy.levine@gmail.com; 401-874-4243

\section{Other Authors}

Dana J. DiScenza, Department of Chemistry, University of Rhode Island, 140 Flagg Road, Kingston, RI 02881; ddiscenza92@gmail.com

Melissa A. Smith, Department of Chemistry, University of Rhode Island, 140 Flagg Road, Kingston, RI 02881; msmith@chm.uri.edu

Lauren E. Intravaia, Department of Chemistry, University of Rhode Island, 140 Flagg Road, Kingston, RI 02881; lintravaia@my.uri.edu 


\section{ABSTRACT}

The detection of phthalates in human biological fluids remains an important research objective because it provides an important measure of an individual's exposure to this class of compounds, which have known deleterious health effects. Moreover, the ability to accomplish such detection in fluids that are easy to collect, such as saliva and urine, provides additional practical advantages. Reported herein is the application of cyclodextrin-promoted fluorescence energy transfer and fluorescence modulation to accomplish precisely such detection: the development of sensitive and selective florescence-based detection methods for phthalates in saliva, an easily collectable human biological fluid. Such saliva-based detection methods occur with high levels of selectivity (100\% differentiation) and sensitivity (limits of detection as low as $0.089 \mu \mathrm{M}$ ), and provide significant potential in the development of practical phthalate detection devices.

Keywords: phthalate esters, saliva, cyclodextrin, fluorescence spectroscopy

\section{INTRODUCTION}

Phthalates are compounds that are of significant concern due to their toxic health effects, particularly as endocrine disruptors (Bowman and Choudhury 2016; Braun 2017). Dibutylphthalate, for example, has been shown to have anti-androgenic effects (Boberg et al. 2015), and diisononylphthalate increases the occurrence of reproductive malformations (Dekant and Bridges 2016). Exposure to phthalates can occur through the use of a broad variety of commercial products (Dodson et al. 2012), including fragrance cosmetics (Pinkas, Goncalves and Aschner 2017), plastics that have been softened by phthalates (Wensing, Uhde and Salthammer 2005), and a variety of vinyl (Wooten and Smith 2013) and food products (Anal and Singh 2007).

Current methods for phthalate detection generally rely on gas chromatography-mass spectrometry (GC-MS) (Russo et al. 2015; Kumar and Sivaperumal 2016) or liquid chromatography-mass spectrometry (LC-MS) (Gallart-Ayala, Nunez and Lucci 2013). While such methods have extremely high sensitivity for a broad variety of phthalates, they require significant time for sample preparation and analysis, as well as financial resources for the high cost instrumentation necessary to conduct such analyses and personnel resources for a highly trained instrument operator (Hartler et al. 2013; Gowda and Djukovic 2014). 
Research in the Levine group has focused on the development of a fundamentally different detection method, using fluorescence-based detection in systems where cyclodextrin can promote favorable intermolecular interactions. In such systems, the presence of the toxicant in close proximity to a high quantum yield fluorophore (where the proximity is facilitated by the cyclodextrin) leads to efficient toxicant-to-fluorophore energy transfer (Serio, Miller and Levine 2013; Serio, Moyano et al. 2015; Serio, Roque, et al. 2015; DiScenza, Culton et al. 2017), in cases where the toxicant is photophysically active, and toxicant-specific, proximity-induced fluorescence modulation (DiScenza and Levine 2016a; DiScenza and Levine 2016b; DiScenza, Verderame and Levine 2016; DiScenza, Lynch and Miller et al. 2017), in cases where the toxicant is not photophysically active. In both cases, the system relies on favorable interactions between the cyclodextrin, toxicant, and fluorophore, and generates fluorescence response signals that are highly toxicant-specific for broad classes of toxicants in multiple complex environments, and highly sensitive in their ability to detect low concentrations of toxicants.

The detection of phthalates using cyclodextrin-promoted fluorescence modulation has not been reported to date, despite the fact that the phthalates have numerous structural features that are expected to facilitate their favorable interactions with cyclodextrin (Okoli et al. 2014). In particular, the hydrophobic components of the phthalates will bind in the hydrophobic cyclodextrin interior (Schneider 2015), whereas the carbonyl moieties will hydrogen bond with one of the cyclodextrin rims, likely the wider one with less steric congestion (Yeguas et al. 2011). Fluorescence modulation-based detection of phthalates would obviate many of the challenges associated with mass spectral detection, including the need for costly instrumentation (many portable and inexpensive fluorescence spectrometers exist), and the need to incorporate chromatographic purification prior to mass spectral detection (a result of the fact that every component in a complex mixture generates its own mass spectral signal).

Whether an individual has been exposed to toxicants, as well as the quantity (both at one time and over prolonged time periods), and identity of those toxicants, is important information for medical professionals in assessing that individual's risk of developing exposure-related disease (Mauriello et al. 2017). Such exposure is generally determined through detecting toxicants and/or toxicant metabolites in an individual's biological fluids, including in urine (Junghoon et al. 2017) and breast milk (Asamoah et al. 2018), and we have previously reported the ability of cyclodextrin-promoted detection to operate in these environments (DiScenza, Gareau et al. 2016; DiScenza, Lynch and 
Verderame et al. 2018). The detection of toxicants in saliva using cyclodextrin-promoted detection has not been reported to date, despite the fact that saliva-based detection has a number of attractive features (Kintz and Samyn 2002), including the non-invasive nature of sample collection and the fact that ingested toxicants in saliva will have undergone limited metabolism and will be easier to detect in their native forms (Elmongy and Abdel-Rehim 2016). One potential complication is that cyclodextrins may undergo hydrolysis by the amylase present in saliva, although literature reports confirm that only $\gamma$-cyclodextrin is likely to undergo such hydrolysis on time scales that are relevant for these detection experiments (Saokham and Loftsson 2017).

Reported herein is the fluorescence detection of a variety of phthalates, in both purified buffer solution and in saliva. This system operates with high sensitivity (micromolar detection limits), selectivity (100\% differentiation even between structurally similar analytes), and general applicability for a variety of phthalate esters as well as for binary mixtures of those esters).

\section{EXPERIMENTAL}

\section{Materials and Methods}

All phthalates and control analytes (compounds 1-5, Figure 1) were purchased from Sigma-Aldrich chemical company and used as received, unless otherwise noted. All cyclodextrins were purchased from Tokyo Chemical Industry (TCI) and used as received. Fluorophore 6 was synthesized following literature-reported procedures (Shepherd et al. 2004). Fluorophores 7 and 8 were purchased from Sigma Aldrich and used as received. Single donor human saliva was purchased from Innovative Research, Inc. and stored in the freezer until use. ${ }^{1} \mathrm{H}$ NMR spectra were obtained using a Bruker $300 \mathrm{MHz}$ spectrometer. UV-Visible spectra were obtained using an Agilent 8453 spectrometer equipped with a photodiode array detector. Fluorescence spectra were obtained using a Shimadzu RF-6000 spectrophotofluorimeter with $3.0 \mathrm{~nm}$ excitation and emission slit widths. GC-MS measurements were obtained using a Shimadzu GC-MS QP2020 gas chromatograph-mass spectrometer. Computational experiments were performed using Spartan 16 software using energy-minimized conformations.

\section{General Procedure for GC-MS Characterization Experiments}

GC-MS sample preparation was conducted following literature-reported procedures (Michelsen et al. 2008). In brief, $1 \mathrm{~mL}$ of saliva and $2 \mathrm{~mL}$ ethyl acetate were added to a glass vial. The vial was 
shaken for 1 minute, and the organic extract was collected in a separate glass vial. This procedure was repeated two times, and the organic extracts were combined. The samples were concentrated using the rotary evaporator at $53{ }^{\circ} \mathrm{C}$ until approximately $200 \mu \mathrm{L}$ sample volume remained.

All GC-MS measurements were performed using a Shimadzu GC-MS QP2020 gas chromatograph-mass spectrometer following literature-reported procedures (Michelsen et al. 2008). The GC-MS operating conditions were as follows: column: Shimadzu SH-Rxi-5SilMS (30 $\mathrm{m} \times 0.25 \mathrm{~mm} \times 0.25 \mu \mathrm{m}$ ); carrier gas: helium at $1.0 \mathrm{~mL} / \mathrm{min}$; oven temperature: $50^{\circ} \mathrm{C}$ increase 50 ${ }^{\circ} \mathrm{C} / \mathrm{min}$ to $120{ }^{\circ} \mathrm{C}$ (5 min) increase $10{ }^{\circ} \mathrm{C} / \mathrm{min}$ to $230{ }^{\circ} \mathrm{C}$ increase $120{ }^{\circ} \mathrm{C} / \mathrm{min}$ to $280{ }^{\circ} \mathrm{C}(1 \mathrm{~min})$; injection temperature: $250{ }^{\circ} \mathrm{C}$, splitting ratio: splitless; electron impact ionization mode; MS ion source temperature: $230{ }^{\circ} \mathrm{C}$; interface temperature: $150{ }^{\circ} \mathrm{C}$; total run time: $30 \mathrm{~min}$.

\section{General Procedure for Fluorescence Modulation Experiments}

For buffer experiments, $2.5 \mathrm{~mL}$ of a $10 \mathrm{mM}$ cyclodextrin solution dissolved in phosphate-bufferedsaline (PBS) was added to a quartz cuvette. For saliva experiments, $1.25 \mathrm{~mL}$ of a $10 \mathrm{mM}$ cyclodextrin solution dissolved in PBS and $1.25 \mathrm{~mL}$ of the saliva sample were combined in a quartz cuvette. A small amount of fluorophore 6-8 $(100 \mu \mathrm{L}, 0.1 \mathrm{mg} / \mathrm{mL}$ in methanol) was added, and the solution was excited at the excitation wavelength of the fluorophore (460 nm for fluorophore 6, $490 \mathrm{~nm}$ for fluorophore 7, and $420 \mathrm{~nm}$ for fluorophore 8). Analytes 1-4 (20 $\mu \mathrm{L}, 1.0$ $\mathrm{mg} / \mathrm{mL}$ solution in methanol) or control analyte $\mathbf{5}$ were added to the cuvette, and the resulting solution was excited at the excitation wavelength of the fluorophore. The fluorescence emission spectra were integrated versus wavenumber on the $\mathrm{X}$-axis, and the fluorescence modulation was measured by the ratio of integrated fluorescence emission of the fluorophore in the presence of analyte divided by the integrated fluorescence emission of the fluorophore in the absence of the analyte, as shown in Eq. (1),

Fluorescence modulation $=F / F_{0}$

where $F$ is the integrated fluorescence emission of the fluorophore in the presence of analyte, and $F_{0}$ is the integrated fluorescence emission of the fluorophore in the absence of analyte. All experiments were performed at room temperature $\left(\sim 22^{\circ} \mathrm{C}\right)$. Control experiments were performed in which $0 \mathrm{mM}$ cyclodextrin solution in PBS was used in place of $10 \mathrm{mM}$ cyclodextrin in PBS. 
For mixture experiments, the above procedure was repeated; however, 1:1 (vol/vol) mixtures of analytes $(10 \mu \mathrm{L}, 1.0 \mathrm{mg} / \mathrm{mL}$ in methanol) were added to the cyclodextrin or saliva-cyclodextrin solutions, and the fluorescence modulation values were calculated for fluorophores 6-8 following Equation 1.

\section{General Procedure for Limit of Detection Experiments}

Limit of detection experiments were performed following literature-reported procedures (Cheng et al. 2016). For buffer experiments, $2.5 \mathrm{~mL}$ of a $10 \mathrm{mM}$ cyclodextrin solution dissolved in phosphate-buffered-saline (PBS) was added to a quartz cuvette. For saliva experiments, $1.25 \mathrm{~mL}$ of a $10 \mathrm{mM}$ cyclodextrin solution dissolved in PBS and $1.25 \mathrm{~mL}$ of the saliva sample were combined in a quartz cuvette. $100 \mu \mathrm{L}$ of fluorophore $6(0.1 \mathrm{mg} / \mathrm{mL}$ in methanol) was added to the solution and excited six times at $460 \mathrm{~nm}$.

Next, $5 \mu \mathrm{L}$ of analyte $(1.0 \mathrm{mg} / \mathrm{mL}$ in methanol) was added, and again the solution was excited at fluorophore 6's excitation wavelength. Six repeat measurements were taken. This step was repeated for $10 \mu \mathrm{L}$ of analyte, $15 \mu \mathrm{L}$ of analyte, $20 \mu \mathrm{L}$ of analyte, $25 \mu \mathrm{L}$ of analyte, $30 \mu \mathrm{L}$ of analyte, $35 \mu \mathrm{L}$ of analyte, and $40 \mu \mathrm{L}$ of analyte.

All of the fluorescence emission spectra were integrated vs. wavenumber on the X-axis, and the calibration curves were generated. The curves plotted the analyte concentration in $\mu \mathrm{M}$ on the $\mathrm{X}$ axis, and the fluorescence modulation ratio on the Y-axis. The curve was fitted to a straight line and the equation of the line was determined. The limit of detection was calculated according to Equation 2.

$\mathrm{LOD}=3\left(\mathrm{SD}_{\text {blank }}\right) / m$

Where $\mathrm{SD}_{\text {blank }}$ is the standard deviation of the blank sample and $m$ is the slope of the calibration curve. In cases where the slope of the trend line was negative, the absolute value of the slope was used to calculate the LOD. In all cases, the LOD was calculated in micromolar.

\section{General Procedure for Array Generation Experiments}

Array analysis was performed using SYSTAT 13 statistical computing software with the following settings: (a) Classical discriminant analysis; (b) Grouping variable: analytes; (c) Predictors: fluorophores; and (d) Long-range statistics: Mahal.

\section{RESULTS AND DISCUSSION}




\section{Saliva Characterization}

The human saliva sample was characterized using GC-MS to determine the presence of inherent chemicals components, including those that are typically found in saliva and those that may be a result of toxicant exposure. Typical saliva components found in the sample include long-chain hydrocarbons typically found in human saliva (Figure 2) (Soini et al. 2010). Moreover, traces of caffeine, commonly found in a wide range of food and beverages (Carvalho et al. 2012; Gerald, Arthur and Adedayo 2014), and ditridecyl phthalate, commonly used as a plasticizer in housing insulation and automobile insulation (Net et al. 2015), were also found in the saliva, and indicate that the single anonymous donor may have consumed caffeine and been exposed to phthalatecontaining insulation prior to donating his/her saliva.

\section{Cyclodextrin Selection}

Cyclodextrins selected for this research include $\alpha$-cyclodextrin and $\beta$-cyclodextrin, dissolved in phosphate buffered saline (PBS, buffered at pH 7.4), as well as a control solution of PBS with no cyclodextrin present. These hosts were selected because they are known to bind at least one of the high quantum yield fluorophores, are readily available, have structural features that will facilitate their interactions with phthalates (via hydrophobic association and/or via intermolecular hydrogen bonding), and are not broken down by the amylase found in saliva. $\gamma$-Cyclodextrin, by contrast, was excluded from these studies due its strong propensity for rapid amylase-induced degradation, despite the fact that it has been shown to facilitate cyclodextrin-promoted fluorescence detection under a broad variety of conditions (Saokham and Loftsson 2017).

\section{Fluorophore Selection}

The fluorophores selected for this research include three common classes of fluorophores: BODIPY, Rhodamine, and Coumarin. Fluorophores 6-8 have been widely used by our group for cyclodextrin-promoted fluorescence-based detection. Moreover, all three of these fluorophores have high quantum yields, good photostability, and have been used in a wide variety of detection schemes (Katerinopoulos 2004; Beija, Afonso and Martinho 2009; Kim, Ren and Jong 2012).

\section{Analyte Selection}

The analytes targeted for detection include phthalate esters that are most commonly found in commercial products, including cosmetics, personal care products, and plasticizers (Koniecki et 
al. 2011; Tarasov et al. 2015). Analyte 1 is commonly found in insect repellent (Karunamoorthi and Sabesan 2010). Analyte 2 has been widely used in perfume fragrances (Chingin et al. 2008). Analyte 3 can be found in nail lacquer (Kwapniewski et al. 2008). Analyte 4 is commonly found in polyvinyl chloride (PVC) pipes (Ma et al. 2014). Because individuals are exposed to these commercial products on a regular basis in their daily lives, there is significant benefit to the individuals, their physicians, and scientific researchers to monitoring and quantifying such exposure to better understand the complex relationship between toxicant exposure and the development of exposure-related disease. Measuring the presence of these highly common phthalates in saliva provides one important way to measure such exposure.

\section{Fluorescence Modulation}

Each cyclodextrin-fluorophore combination was used to enable the detection of specific phthalate esters in both purified buffer systems and human saliva samples. Micromolar concentrations of analytes 1-4 or control analyte 5 were added to each saliva-cyclodextrin-fluorophore or buffercyclodextrin-fluorophore combination, and the degree of fluorescence modulation of fluorophores 6-8 in the presence and absence of analyte was calculated using Equation 1. Each of the three fluorophores selected for analysis displays different behaviors and trends in the modulation results. BODIPY (fluorophore 6) shows the highest changes in fluorescence modulation with the introduction of the target analytes (Table 1). This is likely due to the fact that the predominant way in which BODIPY interacts with cyclodextrin is also one of the key ways in which phthalate esters interact with cyclodextrin, via intermolecular hydrogen bonding of the small molecule with the cyclodextrin rim (Gu et al. 2010; Zhang et al. 2016). Introduction of the analyte therefore results in significant disruption of the BODIPY-cyclodextrin association, which is manifested in the fact that the BODIPY emission spectra changes so dramatically.

Similar intermolecular interactions of BODIPY and phthalates with the cyclodextrin hosts also explains why unique emission characteristics are observed for each of the different cyclodextrin hosts: because the BODIPY-cyclodextrin association and the disruption of such association is so key for determining the unique modulation responses, changes to the identity of the cyclodextrin result in significant changes in the BODIPY's microenvironment, which strongly affects the resulting observable fluorescence emission before and after analyte addition (Figure 3 ). 
The fluorescence emission spectrum of Rhodamine 6G (fluorophore 7) displayed little change with the addition of analyte, for all analytes and all cyclodextrin combinations tested (Table 2). These results indicate a limited association between the Rhodamine $6 \mathrm{G}$ and the analytes, likely as a result of the twisted biphenyl axis that precludes close-range intermolecular interactions (Martinez et al. 2006). Some association between fluorophore 7 and the cyclodextrin hosts is likely, however, as indicated by the fact that the fluorescence intensity of fluorophore 7 is higher in the presence of $\beta$ cyclodextrin compared to the emission in cyclodextrin-free (i.e. PBS) solution (Figure 4). Intermediate values of fluorescence emission were observed in the presence of $\alpha$-cyclodextrin, indicating some (albeit limited) association likely occurs.

The fluorescence emission spectrum of Coumarin 6 (fluorophore 8) displays excimer-like emission peaks, both in the presence of $\alpha$-cyclodextrin and in the absence of any cyclodextrin (pure PBS) (select results shown in Figure 5).

This indicates that fluorophore $\mathbf{8}$ does not bind in the $\alpha$-cyclodextrin cavity, and instead selfassociates in a mostly aqueous solvent environment, resulting in the observed excimer emission. In the presence of $\beta$-cyclodextrin, by contrast, no excimer peaks are observed, which is a direct result of the strong binding of fluorophore $\mathbf{8}$ in the $\beta$-cyclodextrin cavity (binding affinity $\approx 10,000$ $\mathrm{M}^{-1}$ ) (Edetsberger et al. 2011). Moreover, the strong binding also results in limited changes to the fluorescence of fluorophore $\mathbf{8}$ in $\beta$-cyclodextrin with the introduction of phthalate analytes, which is a result of the inability of the phthalates to displace the strongly bound fluorophore from the cyclodextrin cavity.

In addition to the fluorophore-specific trends discussed above, analyte-specific trends were also observed. In particular, the addition of diisononyl phthalate (analyte 4) resulted in the highest degree of fluorescence modulation with fluorophores 6-8 and most dramatic changes in fluorescence emission compared to the other analytes (Figure 6). This is likely a result of the long, hydrophobic isononyl chains binding in the cyclodextrin cavity and promoting strong cyclodextrin-analyte association, as well as significant disruption of the cyclodextrin-fluorophore association. In support of this explanation, literature-reported binding constants of the analytes in $\beta$-cyclodextrin follow the trend that longer alkyl chains result in strong binding affinities, due to the ability of the alkyl chains to bind in the interior cyclodextrin cavity via hydrophobicallyinduced complexation (Table 3). 
Of note, we also tested for any observable effects that could be attributed to the solvent used to dissolve the phthalate analytes, methanol, in the absence of any added analyte. As expected, only minimal changes in the fluorescence spectra with the introduction of small amounts of methanol were observed. Due to the ability of methanol to engage in substantial hydrogen bonding with the heteroaromatic fluorophores and to perturb the local microenvironment, we observed small changes in the fluorescence emission of the fluorophore with the addition of methanol as the control analyte (Jung, Gerharz and Schmitt 2009; Chai et al. 2015). These interactions are fundamentally different from the interactions between the phthalate analytes and the fluorophores, both in terms of the intermolecular forces that underlie such interactions as well as in the magnitude of the fluorescence emission changes. Our use of the solvent methanol, rather than tetrahydrofuran which was used as the solvent in our previous fluorescence studies, was driven by the need to ensure full solubility of all analytes, while requiring full miscibility with the majority aqueous solvent system that is required for the requisite hydrophobically-driven cyclodextrin binding (Nyssen et al. 1987).

\section{Limit of Detection}

The sensitivity of the system was determined by calculating LODs for all buffer- $\beta$-cyclodextrinfluorophore 6-analyte and saliva- $\beta$-cyclodextrin-fluorophore 6-analyte combinations following literature-reported procedures (Cheng et al. 2016), and selected results of these studies are highlighted in Table 4.

In general, LODs for analytes in saliva were slightly higher, reflecting slightly worse sensitivities, than those measured in purified buffer systems. This is likely due to the competitive binding of saliva components, such as long-chain alkanes, caffeine, or the inherent phthalate compound ditridecyl phthalate, with cyclodextrin. In every case, the calculated limits of detection were significantly below literature-reported limits of concern for these compounds. These low limits of detection highlight the extreme sensitivity of this cyclodextrin-promoted fluorescence modulationbased detection method in environments containing ppm-levels of phthalates. However, phthalates, if found in saliva, exist at ppb-range concentrations (Hines et al. 2009). Current work in our laboratory is dedicated towards optimizing our detection method to detect phthalates at even lower concentrations.

\section{Array Generation}


The selectivity of this system was determined by creating statistical arrays using fluorescence modulation results to differentiate between structurally similar analytes in both purified buffer systems and in saliva samples. This array-based analysis showed $100 \%$ differentiation between analytes 1-5 in buffer and saliva for all cyclodextrin-fluorophore combinations, with a specific example of such differentiation highlighted in Figure 7.

The response patterns show well-separated signals between the same analytes in buffer and saliva (i.e. analyte $\mathbf{1}$ in buffer has a signal that is well separated from analyte $\mathbf{1}$ in saliva), and overall, analytes in saliva are grouped separately from those measured in buffer. A specific example includes the grouping of analyte $\mathbf{2}$ in saliva with analyte $\mathbf{3}$ in saliva and analyte $\mathbf{2}$ in buffer with analyte $\mathbf{3}$ in buffer, rather than analyte $\mathbf{2}$ in both samples grouping together.

Additionally, we can also use our statistical arrays to differentiate between different concentrations of analytes (Figure 8).

Figure 8 shows an array generated using different concentrations of analyte 3 with $\beta$-cyclodextrin in buffer and saliva. Interestingly, both the buffer and saliva quantitative arrays led to 100\% differentiation between different concentrations of analyte 4. This selectivity builds on the high sensitivity of our system to be able to induce measurable changes in fluorescence emission of fluorophores with very small changes in analyte concentration. This quantitative array provides both the concentration and the identity of the analyte and highlights the potential for the use of statistical arrays to identify and quantify analytes in unknown samples.

\section{Mixture Experiments}

In complex biological fluids, such as saliva, oftentimes there are several toxicants present in one sample, which can complicate the accurate detection of analytes. To address the question of toxicant detection in complex mixtures, we tested binary mixtures of phthalates using cyclodextrin-promoted fluorescence modulation and found that $100 \%$ differentiation between binary mixtures of analytes was obtained (Figure 9).

Of note, the visual response patterns for analyte mixtures varied depending on the identity of the cyclodextrin hosts. Grouping of analytes is dependent upon cyclodextrin host because the larger $\beta$-cyclodextrin cavity may allow binding or association of both analytes, while the smaller $\alpha$ cyclodextrin cavity may only allow limited association of one analyte in the mixture. In the 
presence of $\alpha$-cyclodextrin (Figure 9A), analyte mixtures of analyte $\mathbf{1}$ and analyte $\mathbf{2}$, analyte $\mathbf{1}$ and analyte $\mathbf{3}$ and analyte $\mathbf{2}$ and analyte $\mathbf{3}$ group closely together. Analytes $\mathbf{3}$ and $\mathbf{4}$ are extremely wellseparated from the other analyte mixtures in the presence of $\alpha$-cyclodextrin. In $\beta$-cyclodextrin (Figure 9B), analyte mixtures containing analytes $\mathbf{1}$ and $\mathbf{2}$ and analytes $\mathbf{1}$ and $\mathbf{4}$ group closely together. Analytes $\mathbf{1}$ and $\mathbf{3}$, analytes $\mathbf{2}$ and $\mathbf{3}$, and analytes $\mathbf{3}$ and $\mathbf{4}$ are well-separated in the presence of $\beta$-cyclodextrin. In the presence of PBS (Figure 9C), no two analyte mixtures are particularly close, each analyte mixture signal is well-separated. Current work in our laboratory is focused on expanding this array-based detection to include ternary and quaternary mixtures of analytes.

\section{CONCLUSIONS}

In conclusion, reported herein is the use of cyclodextrin-promoted fluorescence modulation for the detection of phthalate esters in human saliva. This method is selective $(100 \%$ successful in differentiating structurally similar compounds), sensitive (sub-micromolar detection limits), and generally applicable (for mixtures of analytes). The high selectivity, sensitivity, and general applicability show potential for the development of rapid, on-site detection devices for phthalate esters.

\section{ACKNOWLEDGEMENTS}

Funding is graciously acknowledged from a University of Rhode Island Project Completion Grant and from the University of Rhode Island Department of Chemistry.

\section{ASSOCIATED CONTENT}

Electronic supplementary information is available, containing synthesis of fluorophore $\mathbf{6}$ and summary tables and summary figures for all experiments.

The authors declare no conflict of interest.

\section{REFERENCES}

Anal, A. K., and H. Singh. 2007. Recent advances in microencapsulation of probiotics for industrial applications and targeted delivery. Trends in Food Science and Technology 18 (5):240-251. doi: 10.1016/j.tifs.2007.01.004.

Asamoah, A., D. K. Essumang, J. Muff, S. V. Kucheryavskiy, and E. G. Soegaard. 2018. Assessment of PCBs and exposure risk to infants in breast milk of primiparae and multiparae mothers in an electronic waste hot spot and non-hot spot areas in Ghana. Science of the Total Environment 612:1473-1479. doi: 10.1016/j.scitotenv.2017.08.177. 
Beija, M., C. A. M. Afonso, J. M. G. Martinho. 2009. Synthesis and applications of Rhodamine derivatives as fluorescent probes. Chemical Society Reviews 38 (8):2410-2433. doi: 10.1039/b901612k.

Boberg, J., H. K. L. Johansson, N. Hadrup, K. Dreisig, L. Berthelsen, K. Almstrup, A. M. Vinggaard, and U. Hass. 2015. Perinatal exposure to mixtures of anti-androgenic chemicals causes proliferative lesions in rat prostate. Prostate 75 (2):126-140. doi: $10.1002 /$ pros. 22897 .

Bowman, J. D., and M. Choudhury. 2016. Phthalates in neonatal health: Friend or foe? Journal of Developmental Origins of Health and Disease 7 (6):652-664. doi: $10.1017 / \mathrm{S} 2040174416000349$.

Braun, J. M. 2017. Early-life exposure to EDCs: Role in childhood obesity and neurodevelopment. Nature Reviews Endocrinology 13 (3):161-173. doi: 10.1038/nrendo.2016.186.

Carvalho, J. J., M. G. Weller, U. Panne, and R. J. Schneider. 2012. Monitoring caffeine in human saliva using a newly developed ELISA. Analytical Letters 45 (17):2549-2561. doi: $10.1080 / 00032719.2012 .696226$.

Chai, S., J. Wang, S. Y. Zhu, and S. L. Cong. 2015. Hydrogen-bonding dynamics of photoexcited coumarin 138 and 339 in protic methanol solution: Time-dependent density functional theory study. Computational and Theoretical Chemistry. 1061:6-11. doi: 10.1016/j.comptc.2015.03.005.

Cheng, D., W. Zhao, H. Yang, Z. Huang, X. Liu, and A. Han. 2016. Detection of Hg2+ by a FRET ratiometric fluorescent probe based on a novel BODIPY-RhB system. Tetrahedron Letters 57 (24):2655-2659. doi: 10.1016/j.tetlet.2016.05.015.

Chingin, K., H. Chen, G. Gamez, L. Zhu, and R. Zenobi. 2008. Detection of diethyl phthalate in perfumes by extractive electrospray ionization mass spectrometry. Analytical Chemistry 81 (1):123-129. doi: 10.1021/ac801572d.

Dekant, W., and J. Bridges. 2016. Assessment of reproductive and developmental effects of DINP, DnHP and DCHP using quantitative weight of evidence. Regulatory Toxicology and Pharmacology 81:397-406. doi: 10.1016/j.yrtph.2016.09.032.

DiScenza, D. J., and M. Levine. 2016. Selective detection of non-aromatic pesticides via cyclodextrin-promoted fluorescence modulation. New Journal of Chemistry 40:789-793. doi: $10.1039 / \mathrm{C} 5 \mathrm{NJ} 02357 \mathrm{~B}$.

DiScenza, D. J., and M. Levine. 2016. Sensitive and selective detection of alcohols via fluorescence modulation. Supramolecular Chemistry 28 (11-12):881-891. doi: 10.1080/10610278.2016.1140897.

DiScenza, D. J., E. Culton, M. Verderame, J. Lynch, N. Serio, and M. Levine. 2017. Towards rational chemosensor design through improved understanding of experimental parameter variation and tolerance in cyclodextrin-promoted fluorescence detection. Chemosensors 5 (4):34-49. doi: 10.3390/chemosensors5040034.

DiScenza, D. J., J. Lynch, J. Miller, M. Verderame, and M. Levine. 2017. Detection of organochlorine pesticides in contaminated marine environments via cyclodextrin- 
promoted fluorescence modulation. ACS Omega 2 (12):8591-8599. doi: 10.1021/acsomega.7b00991.

DiScenza, D. J., J. Lynch, M. Verderame, N. Serio, L. Prignano, L. Gareau, and M. Levine. 2018. Efficient fluorescence detection of aromatic toxicants and toxicant metabolites in human breast milk. Supramolecular Chemistry 30 (4):267-277. doi: 10.1080/10610278.2017.1343947.

DiScenza, D. J., L. Gareau, N. Serio, J. Roque, L. Prignano, M. Verderame, and M. Levine. 2016. Cyclodextrin-promoted detection of aromatic toxicants and toxicant metabolites in urine. Analytical Chemistry Letters 6 (4):345-353. doi: 10.1080/22297928.2016.1210021.

DiScenza, D. J., M. Verderame, and M. Levine. 2016. Detection of benzene and alkylated benzene derivatives in fuel contaminated environments. Clean - Soil, Air, Water 44 (12):1621-1627. doi: 10.1002/clen.201600206.

Dodson, R. F., M. Nishioka, L. J. Standley, L. J. Perovich, J. G. Brody, and R. A. Rudel. 2012. Endocrine disruptors and asthma-associated chemicals in consumer products. Environmental Health Perspectives 120 (7):935-943. doi: 10.1289/ehp.1104052.

Edetsberger, M., M. Knapp, E. Gaubitzer, C. Miksch, K. E. Gvichiya, and G. Kohler. 2011. Effective staining of tumor cells by coumarin-6 depends on the stoichiometry of cyclodextrin complex formation. Journal of Inclusion Phenomena and Macrocyclic Chemistry 70 (3-4):327-331. doi: 10.1007/s10847-010-9894-1.

Elmongy, H., and M. Abdel-Rehim. 2016. Saliva as an alternative specimen to plasma for drug bioanalysis. A review. TrAC Trends in Analytical Chemistry 83:70-79. doi: 10.1016/j.trac.07010.

Gallart-Ayala, H., O. Nunez, and P. Lucci. 2013. Recent advances in LC-MS analysis of foodpackaging contaminants. TrAC Trends in Analytical Chemistry 42:99-124. doi: 10.1016/j.trac.2012.09.017.

Gerald, I., D. E. Arthur, and A. Adedayo. 2014. Determination of caffeine in beverages: A review. American Journal of Engineering Research 3 (8):124-137. ISSN: 2320-0847.

Gowda, G. A., and D. Djukovic. 2014. Overview of mass spectrometry-based metabolomics: Opportunities and challenges. Methods in Molecular Biology 1198:3-12. doi: 10.1007/9781-4939-1258-2 1.

Gu, Z. H., D. S. Guo, M. Sun, and Y. Liu. 2010. Effective enlargement of fluorescence resonance energy transfer of poly-porphyrin mediated by $\beta$-cyclodextrin dimers. The Journal of Organic Chemistry 75 (11):3600-3607. doi: 10.1021/jo100351f.

Hartler, J., R. Tharakan, H. C. Koefeler, D. R. Graham, and G. G. Thallinger. 2013. Bioinformatics tools and challenges in structural analysis of lipidomics MS/MS data. Briefings in Bioinformatics 14 (3):375-390. doi: 10.1093/bib/bbs030.

Hattori, K., and S. Murai. 1999. Inclusion of environmental contaminants with $\beta$-cyclodextrin, and adsorption and removal by $\beta$-cyclodextrin polymer. Proceedings of the Ninth International Sympiosium on Cyclodextrins 587-590. doi: 10.1007/978-94-011-4681-4_139. 
Hines, E. P., A. M. Calafat, M. J. Silva, P. Mendola, and S. E. Fenton. 2009. Concentrations of phthalate metabolites in milk, urine, saliva, and serum of lactating North Carolina women. Environmental Health Perspectives 117 (1):86-92. doi: 10.1289/ehp.11610.

Jung, G., S. Gerharz, and A. Schmitt. 2009. Solvent-dependent steady-state fluorescence spectroscopy for searching ESPT-dyes: Solvatochromatism of HPTS revisited. Physical Chemistry Chemical Physics. 11 (9):1416-1426. doi: 10.1039/B816695A.

Junghoon, K., E. Garcia-Esquinas, A. Navas-Acien, and Y. H. Choi. 2017. Blood and urine cadmium concentrations and walking speed in middle-aged and older U.S. adults. Environmental Pollution 232:97-104. doi: 10.1016/j.envpol.2017.09.022.

Karunamoorthi, K., and S. Sabesan. 2010. Laboratory evaluation of dimethyl phthalate treated wristbands against three predominant mosquito (Diptera: Culicidae) vectors of disease. European Review for Medical and Pharmacological Sciences 14 (5):443-448. PMID: 20556923.

Katerinopoulos, H. E. 2004. The coumarin moiety as chromophore of fluorescent ion indicators in biological systems. Current Pharmaceutical Design 10 (30):3835-3852. doi: $10.2174 / 1381612043382666$.

Kim, H. N., W. X. Ren, J. S. Kim, and J. Yoon. 2012. Fluorescent and colorimetric sensors for detection of lead, cadmium, and mercury ions. Chemical Society Reviews 41 (8):32103244. doi: 10.1039/C1CS15245A.

Kintz, P., and N. Samyn. 2002. Use of alternative specimens: drugs of abuse in saliva and doping agents in hair. Therapeutic Drug Monitoring 24 (2):239-246. ISSN: 0163-4356.

Koniecki, D., R. Wang, R. P. Moody, and J. Zhu. 2011. Phthalates in cosmetic and personal care products: Concentrations and possible dermal exposure. Environmental Research 111 (3):329-336. doi: 10.1016/j.envres.2011.01.013.

Kumar, A. R. and P. Sivaperumal. 2016. Analytical methods for the determination of biomarkers of exposure to phthalates in human urine samples. TrAC Trends in Analytical Chemistry 75:151-161. doi: 10.1016/j.trac.2015.06.008.

Kwapniewski, R., S. Kozaczka, R. Hauser, M. J. Sliva, A. M. Calafat, and S. M. Duty. 2008. Occupational exposure to dibutyl phthalate among manicurists. Journal of Occupational and Environmental Medicine 50 (6):705-711. doi: 10.1097/JOM.0b013e3181651571.

Ma, P., B. Yan, Q. Zeng, X. Liu, Y. Wu, M. Jiao, C. Liu, J. Wu, and X. Yang. 2014. Oral exposure of Kunming mice to diisononyl phthalate induces hepatic and renal tissue injury through the accumulation of ROS. Protective effect of melatonin. Food and Chemical Toxicology 68:247-256. doi: 10.1016/j.fct.2014.03.027.

Martinez, V., S. Salleres, J. Banuelos, and F. L. Arbeloa. 2006. Application of polarized fluorescence to evaluate the orientation of dyes adsorbed in layered materials. Journal of Fluorescence 16 (2):233-240. doi: 10.1007/s10895-005-0042-z.

Mauriello, M. C., C. Sbordone, P. Montuori, R. Alfano, M. Triassi, I. Iavicoli, and M. Manno. 2017. Biomonitoring of toxic metals in incinerator workers: a systematic review. Toxicology Letters 272:8-28. doi: 10.1016/j.toxlet.2017.02.021. 
Michelsen, V. B., G. Moe, M. B. Strom, E. Jensen, and H. Lygre. 2008. Quantitative analysis of TEGDMA and HEMA eluted into saliva from two dental composites by use of GC/MS and tailor-made internal standards. Dental Materials 24 (6):724-731. doi: 10.1016/j.dental.2007.08.002.

National Service Center for Environmental Publications (NSCEP). 1978. Phthalate esters ambient $\begin{array}{lllll}\text { water } & \text { criteria. } & \text { Accessed }\end{array}$ https://nepis.epa.gov/Exe/ZyPURL.cgi?Dockey=910000MZ.txt

Net, S., R. Sempre, A. Delmont, A. Paluselli, and B. Ouddane. 2015. Occurrence, fate, behavior and ecotoxicological state of phthalates in different environmental matrices. Environmental Science \& Technology 49 (7):4019-4035. doi: 10.1021/es505233b.

Nyssen, G. A., E. T. Miller, T. F. Glass, C. R. Quinn, J. Underwood, and D. J. Wilson. 1987. Solubilities of hydrophobic compounds in aqueous-organic solvent mixtures. Environmental Monitoring and Assessment 9 (1):1-11. doi: 10.1007/BF00394211.

Okoli, C. P., G. O. Adewuyi, Q. Zhang, P. N. Diagboya, and Q. Guo. 2014. Mechanism of dialkyl phthalates removal from aqueous solution using $\gamma$-cyclodextrin and starch based polyurethane polymer adsorbents. Carbohydrate Polymers 114:440-449. doi: 10.1016/j.carbpol.2014.08.016.

Pinkas, A., C. L. Goncalves, and M. Aschner. 2017. Neurotoxicity of fragrance compounds: A review. Environmental Research 158:342-349. doi: 10.1016/j.envres.2017.06.035.

Russo, M. V., P. Avino, L. Perugini, and I. Notardonato. 2015. Extraction and GC-MS analysis of phthalate esters in food matrices: A review. RSC Advances 5:37023-37043. doi: 10.1039/C5RA01916H.

Saokham, P., and T. Loftsson. 2017. $\gamma$-Cyclodextrin. International Journal of Pharmaceutics 516 (1-2):278-292. doi: 10.1016/j.jpharm.2016.10.062.

Schneider, H. J. 2015. Dispersive interactions in solution complexes. Accounts of Chemical Research 48 (7):1815-1822. doi: 10.1021/acs.accounts.5b00111.

Serio, N., D. F. Moyano, V. M. Rotello, and M. Levine. 2015. Array-based detection of persistent organic pollutants via cyclodextrin promoted energy transfer. Chemical Communications 51:11615-11618. doi: 10.1039/C5CC04153H.

Serio, N., J. Roque, A. Badwal, and M. Levine. 2015. Rapid and efficient pesticide detection via cyclodextrin-promoted energy transfer. Analyst 140:7503-7507. doi: 10.1039/C5AN01471A.

Serio, N., K. Miller, and M. Levine. 2013. Efficient detection of polycyclic aromatic hydrocarbons and polychlorinated biphenyls via three-component energy transfer. Chemical Communications 49 (42):4821-4823. doi: 10.1039/C3CC40534F.

Shepherd, J. L., E. Chung, C. W. Sinclair, M. S. Workentin, and D. Bizzotto. 2004. Selective reductive desorption of a SAM-coated gold electrode revealed using fluorescence microscopy. Journal of the American Chemical Society 126 (26):8329-8335. doi: 10.1021/ja0494095.

Soini, H. A., I. Klouckova, D. Wiesler, E. Oberzaucher, K. Grammer, S. J. Dixon, Y. Xu, R. G. Brereton, D. J. Penn, and M. V. Novotny. 2010. Analysis of volatile organic compounds 
in human saliva by static sorptive extraction method and gas chromatography-mass spectrometry. Journal of Chemical Ecology 36 (9):1035-1042. doi: 10.1007/s10886-0109846-7.

Tarasov, A. E., G. V. Malkov, M. L. Bubnova, Y. I. Estrin, and E. R. Badamshina. 2015. Influence of curing conditions and dibutyl phthalate concentration on the properties of cured epoxy resin. Russian Journal of Applied Chemistry 88 (12):2015-2020. doi: 10.1134/S10704272150120174.

Wensing, M., E. Uhde, and T. Salthammer. 2005. Plastic additives in the indoor environment flame retardants and plasticizers. Science of the Total Environment 339 (1-3):19-40. doi: 10.1016/j.scitotenv.2004.10.028.

Wooten, K. J., and P. N. Smith. 2013. Canine toys and training devices as sources of exposure to phthalates and bisphenol A: Quantitation of chemicals in leachate and in vitro screening for endocrine activity. Chemosphere 93 (10):2245-2253. doi: 10.1016/j.chemosphere.2013.07.075.

Yeguas, V., M. Altarsha, G. Monard, R. Lopez, and M. F. Ruiz-Lopez. 2011. Peptide binding to $\beta$-cyclodextrins: Structure, dynamics, energetics, and electronic effects. Journal of Physical Chemistry A 115 (42):11810-11817. doi: 10.1021/jp2053037.

Zhang, Q., Y. Cai, X. J. Wang, J. L. Xu, Z. Ye, S. Wang, P. H. Seeberger, and J. Yin. 2016. Targeted photodynamic killing of breast cancer cells employing heptamannosylated $\beta$ cyclodextrin-mediated nanoparticle formation of an adamantane-functionalized BODIPY photosensitizer. ACS Applied Materials \& Interfaces 8 (49):33405-33411. doi: 10.1021/acsami.6b13612. 


\section{TABLES}

Table 1. Fluorescence modulation values for analytes with BODIPY ${ }^{\mathrm{a}}$

\begin{tabular}{|c|c|c|c|c|c|c|}
\hline \multirow[t]{2}{*}{ Analyte } & \multicolumn{3}{|c|}{ Buffer } & \multicolumn{3}{|c|}{ Saliva } \\
\hline & $\begin{array}{c}\text { Alpha- } \\
\text { cyclodextrin }\end{array}$ & $\begin{array}{c}\text { Beta- } \\
\text { cyclodextrin }\end{array}$ & $\begin{array}{c}\text { Phosphate } \\
\text { Buffered } \\
\text { Saline }\end{array}$ & $\begin{array}{c}\text { Alpha- } \\
\text { cyclodextrin }\end{array}$ & $\begin{array}{c}\text { Beta- } \\
\text { cyclodextrin }\end{array}$ & $\begin{array}{c}\text { Phosphate } \\
\text { Buffered } \\
\text { Saline }\end{array}$ \\
\hline $\begin{array}{l}\text { Dimethyl } \\
\text { phthalate }\end{array}$ & $0.98 \pm 0.02$ & $1.15 \pm 0.02$ & $1.43 \pm 0.03$ & $1.15 \pm 0.02$ & $1.09 \pm 0.02$ & $1.21 \pm 0.04$ \\
\hline $\begin{array}{c}\text { Diethyl } \\
\text { phthalate }\end{array}$ & $1.12 \pm 0.04$ & $1.01 \pm 0.00$ & $1.07 \pm 0.01$ & $1.06 \pm 0.06$ & $0.99 \pm 0.02$ & $1.11 \pm 0.02$ \\
\hline $\begin{array}{c}\text { Dibutyl } \\
\text { phthalate }\end{array}$ & $1.15 \pm 0.04$ & $1.27 \pm 0.0$ & $1.77 \pm 0.05$ & $1.12 \pm 0.02$ & $1.11 \pm 0.03$ & $1.20 \pm 0.03$ \\
\hline $\begin{array}{l}\text { Diisononyl } \\
\text { phthalate }\end{array}$ & $2.62 \pm 0.06$ & $3.96 \pm 0.12$ & $2.16 \pm 0.04$ & $1.95 \pm 0.02$ & $1.69 \pm 0.15$ & $1.77 \pm 0.15$ \\
\hline Methanol & $0.96 \pm 0.01$ & $1.19 \pm 0.08$ & $1.14 \pm 0.04$ & $0.99 \pm 0.01$ & $1.13 \pm 0.03$ & $0.96 \pm 0.08$ \\
\hline
\end{tabular}

${ }^{a}$ All results represent an average of results from four trials for each sample. Fluorescence modulation values were calculated using Equation 1. 
Table 2. Fluorescence modulation values for analytes with Rhodamine $6 \mathrm{G}^{\mathrm{a}}$

\begin{tabular}{|c|c|c|c|c|c|c|}
\hline \multirow{2}{*}{ Analyte } & \multicolumn{3}{|c|}{ Buffer } & \multicolumn{2}{c|}{ Saliva } \\
\cline { 2 - 7 } & $\begin{array}{c}\text { Alpha- } \\
\text { cyclodextrin } \\
\text { cyclodextrin }\end{array}$ & $\begin{array}{c}\text { Beta- } \\
\text { Buffered } \\
\text { Saline }\end{array}$ & $\begin{array}{c}\text { Alpha- } \\
\text { cyclodextrin }\end{array}$ & $\begin{array}{c}\text { Beta- } \\
\text { cyclodextrin }\end{array}$ & $\begin{array}{c}\text { Phosphate } \\
\text { Buffered } \\
\text { Saline }\end{array}$ \\
\hline $\begin{array}{c}\text { Dimethyl } \\
\text { phthalate }\end{array}$ & $0.99 \pm 0.00$ & $1.00 \pm 0.00$ & $0.98 \pm 0.00$ & $0.98 \pm 0.00$ & $1.01 \pm 0.00$ & $0.98 \pm 0.00$ \\
\hline $\begin{array}{c}\text { Diethyl } \\
\text { phthalate }\end{array}$ & $0.99 \pm 0.00$ & $0.99 \pm 0.00$ & $0.98 \pm 0.00$ & $0.99 \pm 0.00$ & $1.00 \pm 0.00$ & $0.99 \pm 0.00$ \\
\hline $\begin{array}{c}\text { Dibutyl } \\
\text { phthalate }\end{array}$ & $1.00 \pm 0.00$ & $0.99 \pm 0.00$ & $0.99 \pm 0.00$ & $1.00 \pm 0.00$ & $1.00 \pm 0.01$ & $0.98 \pm 0.00$ \\
\hline $\begin{array}{c}\text { Diisononyl } \\
\text { phthalate }\end{array}$ & $1.00 \pm 0.00$ & $1.00 \pm 0.00$ & $0.98 \pm 0.00$ & $1.00 \pm 0.00$ & $1.02 \pm 0.00$ & $0.98 \pm 0.00$ \\
\hline Methanol & $0.97 \pm 0.00$ & $1.00 \pm 0.00$ & $0.97 \pm 0.00$ & $0.99 \pm 0.00$ & $0.99 \pm 0.00$ & $0.99 \pm 0.00$ \\
\hline
\end{tabular}

${ }^{a}$ All results represent an average of results from four trials for each sample. Fluorescence modulation values were calculated using Equation 1. 
Table 3. Literature-reported binding constants for analytes with $\beta$-cyclodextrin ${ }^{\mathrm{a}}$

\begin{tabular}{|c|c|}
\hline Analyte & Binding Constant $\left(\mathbf{M}^{-\mathbf{1}}\right)$ \\
\hline Dimethyl & 82 \\
phthalate & 107 \\
\hline Diethyl & \\
\hline phthalate & 1160 \\
phthalate & \\
\hline Methanol & $b$ \\
\hline
\end{tabular}

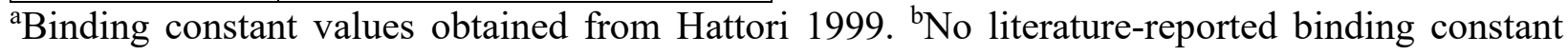
available. 
Table 4. Limits of detection for analytes with BODIPY and $\beta$-cyclodextrin in buffer and saliva ${ }^{a}$

\begin{tabular}{|c|c|c|c|}
\hline Analyte & $\begin{array}{c}\text { LOD in Buffer } \\
(\mathbf{m g} / \mathbf{L})\end{array}$ & $\begin{array}{c}\text { LOD in Saliva } \\
(\mathbf{m g} / \mathbf{L})\end{array}$ & Exposure Limit (mg/L) $^{b}$ \\
\hline $\begin{array}{c}\text { Dimethyl } \\
\text { phthalate }\end{array}$ & $1.68 \pm 0.32$ & $3.31 \pm 0.21$ & 160 \\
\hline $\begin{array}{c}\text { Diethyl } \\
\text { phthalate }\end{array}$ & $0.49 \pm 0.01$ & $0.62 \pm 0.04$ & 60 \\
\hline $\begin{array}{c}\text { Dibutyl } \\
\text { phthalate }\end{array}$ & $0.28 \pm 0.01$ & $0.41 \pm 0.04$ & 5 \\
\hline $\begin{array}{c}\text { Diisononyl } \\
\text { phthalate }\end{array}$ & $0.037 \pm 0.001$ & $0.18 \pm 0.04$ & $c$ \\
\hline
\end{tabular}

${ }^{a}$ Limits of detection were calculated using the procedures in Cheng 2016; see Electronic Supporting Information for more details. Errors are shown with enough significant figures to accurately capture the errors ${ }^{\mathrm{b}}$ Exposure limits from National Service Center for Environmental Publications $1978 ;{ }^{\mathrm{c}}$ No established exposure limit currently exists. 


\section{FIGURE CAPTIONS}

Figure 1. Structures of analytes 1-4, control analyte 5, and fluorophores 6-8

Figure 2. GC-MS spectrum of the human saliva sample

Figure 3. Fluorescence changes of BODIPY upon introduction of (A) no analyte in buffer, (B) dimethyl phthalate in buffer, (C) no analyte in saliva, and (D) dimethyl phthalate in saliva. The black line represents $\alpha$-cyclodextrin, the red line represents $\beta$-cyclodextrin, and the blue line represents phosphate buffered saline (PBS). Analytical conditions: BODIPY $(100 \mu \mathrm{L}, 0.1 \mathrm{mg} / \mathrm{mL}$ in THF); dimethyl phthalate $(20 \mu \mathrm{L}, 1.0 \mathrm{mg} / \mathrm{mL}$ in THF); excitation wavelength: $460 \mathrm{~nm}$; emission range: $470-800 \mathrm{~nm}$; excitation and emission slit widths: $3.0 \mathrm{~nm}$.

Figure 4. Fluorescence emission of Rhodamine $6 \mathrm{G}$ upon introduction of (A) no analyte in buffer, (B) diethyl phthalate in buffer, (C) no analyte in saliva, and (D) diethyl phthalate in saliva. The black line represents $\alpha$-cyclodextrin, the red line represents $\beta$-cyclodextrin, and the blue line represents phosphate buffered saline (PBS). Analytical conditions: Rhodamine 6G (100 $\mu \mathrm{L}, 0.1$ $\mathrm{mg} / \mathrm{mL}$ in THF); diethyl phthalate $(20 \mu \mathrm{L}, 1.0 \mathrm{mg} / \mathrm{mL}$ in THF); excitation wavelength: $490 \mathrm{~nm}$; emission range: 500-800 $\mathrm{nm}$; excitation and emission slit widths: $3.0 \mathrm{~nm}$.

Figure 5. Fluorescence changes of Coumarin 6 upon introduction of dibutyl phthalate with (A) $\alpha$ cyclodextrin, (B) $\beta$-cyclodextrin, and (C) phosphate buffered saline (PBS). The black line represents buffer and the red line represents saliva. Analytical conditions: Coumarin $6(100 \mu \mathrm{L}$, $0.1 \mathrm{mg} / \mathrm{mL}$ in THF); dibutyl phthalate $(20 \mu \mathrm{L}, 1.0 \mathrm{mg} / \mathrm{mL}$ in THF); excitation wavelength: 420 $\mathrm{nm}$; emission range: $430-800 \mathrm{~nm}$; excitation and emission slit widths: $3.0 \mathrm{~nm}$.

Figure 6. Fluorescence changes of (A) BODIPY, (B) Rhodamine 6G, and (C) Coumarin 6 upon introduction of diisononyl phthalate in saliva. The black line represents $\alpha$-cyclodextrin, the red line represents $\beta$-cyclodextrin, and the blue line represents phosphate buffered saline (PBS). Analytical conditions: BODIPY, Rhodamine, and Coumarin $6(100 \mu \mathrm{L}, 0.1 \mathrm{mg} / \mathrm{mL}$ in THF); diisononyl phthalate $(20 \mu \mathrm{L}, 1.0 \mathrm{mg} / \mathrm{mL}$ in THF); excitation wavelength: BODIPY at $460 \mathrm{~nm}$, Rhodamine $6 \mathrm{G}$ at $490 \mathrm{~nm}$, and Coumarin 6 at $420 \mathrm{~nm}$; emission range: BODIPY from $470 \mathrm{~nm}$ to $800 \mathrm{~nm}$, Rhodamine 6G from $500 \mathrm{~nm}$ to $800 \mathrm{~nm}$, and Coumarin 6 from $430 \mathrm{~nm}$ to $800 \mathrm{~nm}$; excitation and emission slit widths: $3.0 \mathrm{~nm}$.

Figure 7. Array-based detection of analyteswith $\beta$-cyclodextrin in buffer and saliva using BODIPY, Rhodamine 6G, and Coumarin 6 as predictors

Figure 8. Array-based detection of various concentrations of dibutyl phthalate with $\beta$-cyclodextrin in (A) buffer and (B) saliva using BODIPY, Rhodamine 6G, and Coumarin 6 as predictors

Figure 9. Array-based detection of mixtures of analytes in the presence of (A) $\alpha$-cyclodextrin; (B) $\beta$-cyclodextrin, and (C) PBS using fluorophores BODIPY, Rhodamine 6G, and Coumarin 6 as predictors 